\title{
A Randomized Controlled Trial of Contingency Management Therapy in Enhancing Treatment Engagement in a Drug Rehabilitation Centre
}

\author{
Mohamad Salleh Abdul Ghani \\ Mohamad Isa Amat \\ Mohd Khairul Anuar Rahimi \\ Haslee Sharil Lim Abdullah \\ Muhammad Khairi Mahyuddin
}

Faculty of Leadership and Management

Universiti Sains Islam Malaysia (USIM)

\begin{abstract}
Background and aims: Contingency management $(C M)$ is a highly effective intervention and has been widely tested and evaluated in the context of substance abuse treatment worldwide. However, this approach is still new in developing countries such as Malaysia. This article aims at determining the effect of CM on treatment engagement within a psychosocial program in a compulsory treatment center in Malaysia. Methods: A randomized controlled trial design was used in this study. A total of 45 methamphetamine-dependent inmates were selected as subjects and randomly assigned into two groups namely the experimental group of treatment as usual + contingency management $(T A U+C M)(n=22)$ and the controlled group of treatment as usual (TAU) (n=23). The TAU+CM group followed a 12-week CM intervention and 4-week follow up session without CM reinforcement. Meanwhile, the TAU group went through 16 weeks of usual psychosocial session implemented in the center. Measurements: The primary outcome of the study was treatment engagement within treatment sessions. It is measured by three parameters which are the assessment of (1) homework completion, (2) active participation and (3) understanding of treatment session. CM reinforcement in a form of star stickers with certain monetary value was given to subjects who achieved the targeted goal in the TAU+CM group. The value of the stickers started from RM2.00 and the magnitude would increase every four weeks. No reinforcement was given in the TAU group. Findings: The TAU+CM group seemed to enhance the treatment engagement within the 12-week psychosocial program. Overall, both groups have showed an increased treatment engagement with the TAU+CM group has a higher achievement than the TAU group. However, the overall differences between the groups were not statistically significant, thus rejecting the main hypothesis of the study which hypothesized that there will be significant differences in treatment engagement between the TAU+CM group and TAU group. Conclusion: The study of CM in a special population, especially in a compulsory treatment center, has been very challenging for researchers. Some studies had similar insignificant result could be due to the special population effect which needs to be further investigated in future studies.
\end{abstract}

Keyword: Contingency management, substance use disorders, addiction treatment and rehabilitation, effectiveness.

\section{Introduction}

Substance use disorders (SUDs) are complicated and challenging problems faced all over the world (United Nations Office on Drugs and Crime, 2016). These disorders undermine health and longevity and are economically costly. In Malaysia, research conducted by Universiti Utara Malaysia in 2009 showed that Malaysia has lost more than RM8.65 billion spending on drug enforcement, treatment, and rehabilitation. The value included the loss of productivity and cost caused by crime related to drug abuse (Ali, Hassan, \& Karim, 2009). Despite many initiatives done by the government to curb the issue, the problem continues and seems to be increasing each year. Based on information released by Malaysia's National Anti-Drugs Agency (NADA), a total of 100,938 addicts were detected during the 5-year period from 2010 to 2014. 
Among the addicts, $97 \%$ or 98,062 were men and $3 \%$, or 2,876 were women (National Anti-Drugs Agency, 2016). The Malaysian government has always been working hard to address these issues through the four main strategies of Malaysia's National Drug Policy (National Anti-Drugs Agency, 2015). The strategies include prevention; treatment and rehabilitation; enforcement and international cooperation with the objective of reducing the demand and the supply of dangerous drugs in the country. In the aspect of demand reduction, the government has focused on implementing various treatment approaches, rehabilitation programs and prevention campaigns throughout the country. NADA often review the methods of treatment used in helping to treat drug addicts. However, low treatment motivation among rehab inmates and treatment compliance remain as major obstacles. An obvious contributor to this is the fact that most of substance users currently under rehabilitation in Malaysia are doing so under the court orders (Ting Chie, Lian Tam, Bonn, Minh Dang, \& Khairuddin, 2016). Thus, even with somewhat improved treatment options, self-motivation to change remains an important challenge to tackle (Ting Chie et al., 2016). Based on that notion, this article is interested in exploring the efficacy of contingency management (CM) approach which is an evidence-based approach that has been recognized as one of best treatment approach in substance abuse treatment (U.S. Department of Health and Human Services, 1999). CM interventions are designed based on the principles to establish a behavior using reward or positive reinforcement thus diminished the client association of treatment with punishment. According to Higgins \& Silverman, (2008), $\mathrm{CM}$ has shown impressive levels of efficacy across a wide range of SUDs. Many researchers agreed that CM has a high level of efficacy in the treatment and rehabilitation of substance use disorders (Davis, Kurti, Skelly, Redner, White \& Higgins, 2016). However, these approaches have not yet been studied in Malaysia.

\section{Methods}

\subsection{Participants}

The study was conducted in a compulsory treatment center known as the Cure and Care Rehabilitation Centre (CCRC) located in the state of Selangor. A total of 94 patients were screened for the study and 45 of them met with inclusion criteria and selected as subjects for the study. The subjects were selected based on the following criteria: Entering CCRC for the first time; Aged between 19 to 39 years old; Participate in psychosocial programs; Be able to read and write; Male; Malay ethnicity; Muslims; Free from any psychiatric disorder or chronic disease; Did not participate in any drug substitution therapy, and; Agree to join the study and signing a written consent form. The study has been approved by the Universiti Sains Islam Malaysia's ethics board committee (USIM/JKEP-2018-35) and all aspects of the study had been explained to the subjects prior to the study.

\subsection{Treatment program}

The CCRC's treatment program consists of psychosocial session based on the adoption and adaptation of the Model Matrix programs from the Matrix Institute in Los Angeles, California. It incorporated elements of relapse prevention, cognitive-behavioral, psychoeducation and family approaches, as well as the 12-step program. This evidence-based approach has been adopted and adapted into Malaysian addiction treatment setting in the year 2007 and pilot study of the model effectiveness have been done and found that clients who enrolled in the Matrix program show positive changes in terms of their recovery (Mahmood Nazar Mohamed, Maizurah Zakaria, \& Salleh Hj Ghani, 2009).

The psychosocial program session was conducted weekly and held approximately 90 minutes each session. In the session, subjects were given a certain topic to discuss together with the rehabilitation officer. Homework was provided after each session and to be submitted in the next session. In the next session, subjects were asked to answer a simple quiz to test their level of understanding on the previous topic. Subject who manages to answer $80 \%$ to $100 \%$ correctly from the quiz and completed their homework, earned them star stickers for each task. The subject had also been given star sticker for active participation during the session. Each psychosocial session is conducted in a casual, didactic manner and conducted by a qualified rehabilitation officer from the center.

\subsection{Study design}

The study used a 16-week randomized controlled trial design comparing two study group which is the experimental group of TAU+CM group versus the controlled group of TAU. The assessment was made on the 45 subjects as the baseline prior to the real study. They were then randomly assigned into two group by using excel random number generator. The TAU+CM group received psychosocial with $\mathrm{CM}$ intervention meanwhile, TAU group only received psychosocial intervention without CM reinforcement. 
The TAU+CM group went through a 12-week intervention with $\mathrm{CM}$ reinforcement and another four weeks without $\mathrm{CM}$ as a follow-up phase. For the TAU group, the subjects went through a 16-week of TAU without any $\mathrm{CM}$ reinforcement. No blinding was used on the rehabilitation officer. However, information regarding the intervention in the TAU+CM group was refrained from the TAU group. Proper precautions had been taken to reduce the threat on external validity such as separating both groups and preventing them from sharing their experience with the other group or inmates. The study design is presented in Figure 1.

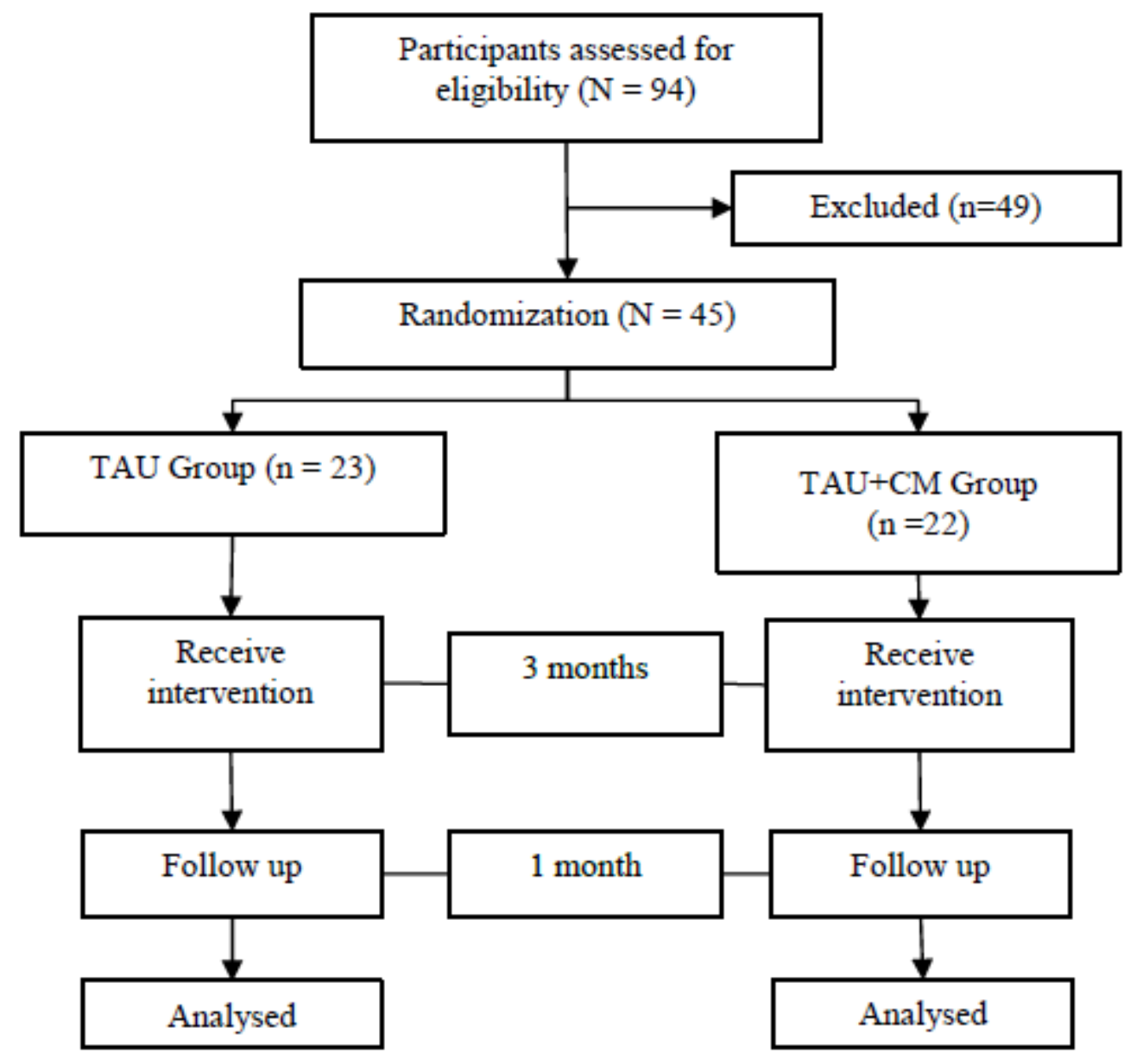

Figure 1: Flowchart of the subject's participation

In this study, CM focused on treatment engagement based on Bartholomew, Rowan-Szal, and Simpson, (2005). In a controlled setting such as CCRC's context, behavior changes were monitored within the treatment session such as homework completion and participation in the session. Rewards or reinforcer in the form of star stickers were given according to the treatment engagement parameters: (1) the completion of homework or assignment; (2) participation in the sessions; and (3) the ability to understand and recall the previous session. For each accomplishment, a star sticker would be added on the subject's chart (Figure 2). The star sticker has a monetary value which can be exchanged for certain items available in the CCRC. The value of each star sticker begins with RM2.00 and would increase every four weeks to the value of RM5.00. CM implementation in this study was developed based on the protocol established by Petry, (2000). For the period of 12 weeks, subjects from the TAU+CM group would have a chance to get star stickers for the three targeted behavior achieved every week. For the first four weeks, the value of each sticker was equivalent to RM2.00 and at the end of the fourth week, they had a chance to redeem items made available with the same value of the stickers collected. The magnitude of the value of the sticker will increase every four weeks until the end of week 12 . From week five to week eight the value of star stickers was equal to RM3.00 and from week nine to week 12 the value of the sticker was RM5.00. The subject who collected the most stickers after every four weeks get a bonus sticker equivalent to RM10.00. The maximum value of sticker collected by the end of the study for one person was RM150.00. 


\section{Weekly Star Chart}

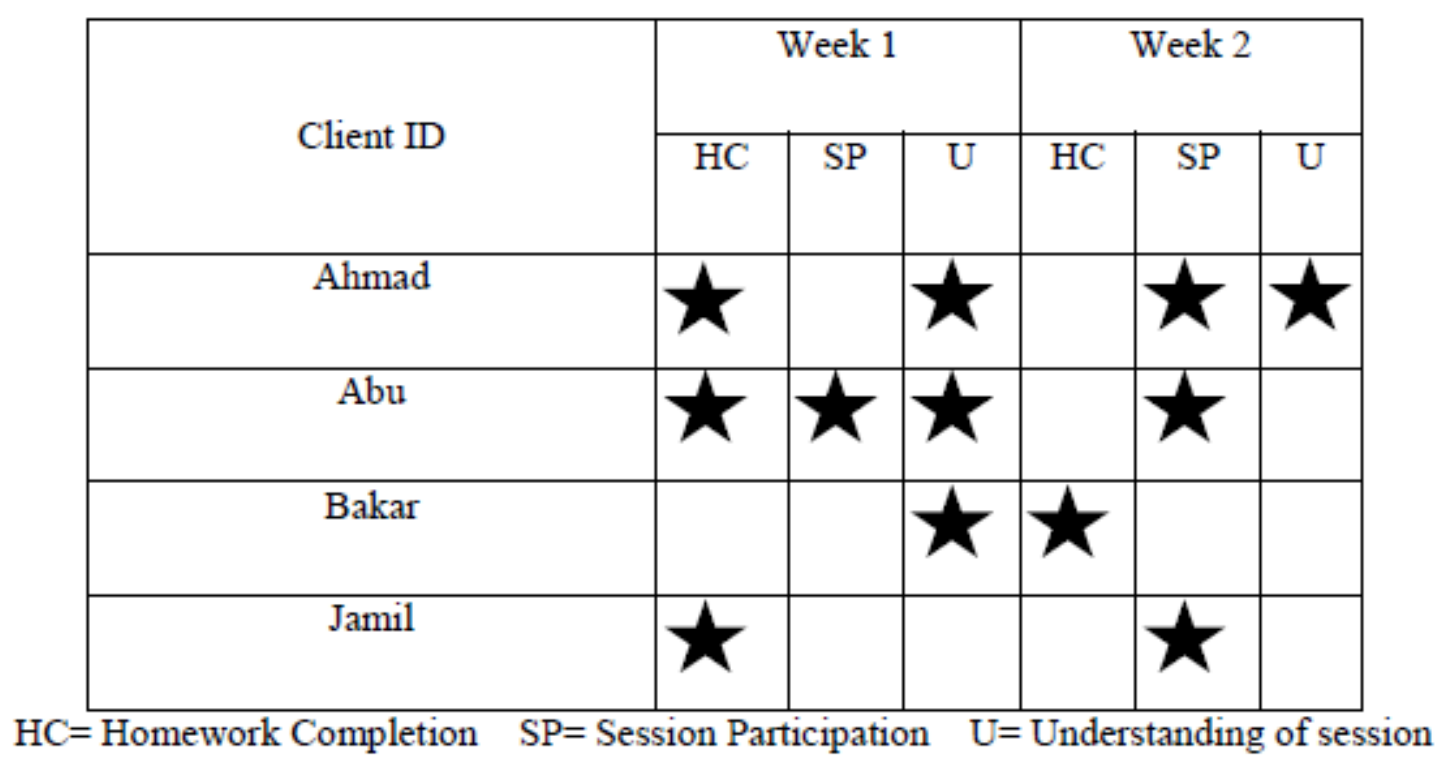

Figure 2: Star Chart (Bartholomew, Rowan-Szal \& Simpson, 2005)

\subsection{Data analysis}

The study used $\mathrm{G}^{*}$ Power tools analysis to determine the appropriate number of subject in the study. For this research, researchers have set the alpha, power, and effect size values as $\alpha=0.05$, power $=0.80$, and effect size $=$ 0.50 based on Daly \& Cohen, (1977) and Lipsey, (1990). Based on the G*Power analysis, the appropriate number of subjects for one group is 18 people or 36 people for both groups, thus 45 subjects for the study are suitable for this study. Statistical analysis used in this study was performed using IBM-SPSS software (version 22 for windows). Group comparison for baseline characteristic was made using $t$-test for continuous data, $\chi^{2}$ test for nominal and categorical data. Generalized estimating equation (GEE) analysis was performed to examine the individual performance of the three parameters of treatment engagement. The overall mean of the three parameters will then be computed and analyze using GEE to get the overall results of treatment engagement.

\section{Results}

\subsection{Baseline characteristics}

Socio-demographic characteristic of the 45 subjects are based on the inclusion criteria determined by the researcher. However, a few extra information was added such as education level, marital status, and occupational information to further explore the background of the subjects. Overall, $100 \%$ of subjects are male with an average age of 28 years old with Malay ethnicity and Islam in religion. Around 50\% (CM+TAU) to 65\% (TAU) have an education level of Sijil Pelajaran Malaysia (SPM). More than 60\% of them are single and less than 20\% of them are working and has an average income of RM1500 to RM2200 (Table 1). Clinical characteristic at baseline showed an average drug use starting age at 23 years old for the TAU+CM group and at 24 years old in the TAU group with a period of addiction of 4 to 5 years. Reason for drugs use was difference between both groups with $50 \%$ of TAU+CM group are caused by peer influence and $61 \%$ from the TAU group, because they wanted to try. All subjects enter the CCRC for treatment for the first time and are all methamphetamine user. Clinical assessment using the Severity of Dependence Scale (SDS) show most subjects with a mean score of 1.4 which is in the moderate level of severity. Beside SDS, the study also uses Treatment Motivation Questionnaire (TMQ), to assess the level of motivation during treatment. Subjects in the study showed to have a moderate level of motivation during baseline. Comparison between both groups showed that there are no significant differences between both groups which showed that randomization has worked (Table 2). 
Table 1: Baseline socio-demographic characteristics

\begin{tabular}{lll}
\hline Variables $^{\text {a }}$ & $\begin{array}{l}\text { CM+TAU } \\
\text { Experimental Group } \\
(\mathrm{n}=22)\end{array}$ & $\begin{array}{l}\text { TAU } \\
\text { Controlled Group } \\
(\mathrm{n}=23)\end{array}$ \\
\hline Gender (\% male) & 100 & 100 \\
Age & $28.7(4.6)$ & $28.9(4.8)$ \\
Ethnicity (\% Malays) & 100 & 95.7 \\
Religion (\% Islam) & 100 & 100 \\
Education level (\%) & & 0 \\
$\quad$ Diploma & 9.1 & 65.2 \\
$\quad$ SPM & 50.9 & 21.7 \\
$\quad$ PMR & 27.3 & 13.0 \\
$\quad$ Primary school & 13.6 & 60.9 \\
Marital status (\%) & & 30.4 \\
$\quad$ single & 68.2 & 8.7 \\
$\quad$ married & 31.8 & 21.0 \\
$\quad$ divorced & 0 & $2215.7(2014.8)$ \\
Occupation status (\% working) & 16.0 & \\
Average income & $1577.3(946.1)$ &
\end{tabular}

${ }^{\text {a }}$ Values are mean (SD), otherwise declared.

Table 2: Baseline clinical characteristics

\begin{tabular}{lll}
\hline Variables $^{\text {a }}$ & $\begin{array}{l}\text { CM+TAU } \\
\text { Experimental Group } \\
(\mathrm{n}=22)\end{array}$ & $\begin{array}{l}\text { TAU } \\
\text { Controlled Group } \\
(\mathrm{n}=23)\end{array}$ \\
\hline $\begin{array}{l}\text { Drugs use starting age } \\
\text { Period of addiction }\end{array}$ & $\begin{array}{l}23.4(5.3) \\
24.3(5.2)\end{array}$ \\
$\begin{array}{l}\text { Reason for using (\%) } \\
\text { Peer influence }\end{array}$ & 50.9 & $4.1(2.0)$ \\
$\quad$ Wanted to try & 40.9 & 34.8 \\
$\quad$ Family problem & 4.5 & 60.9 \\
$\quad$ Others & 4.5 & 4.3 \\
First time getting treatment in CCRC (\%) & 100 & 0 \\
Type of drug (\% meth) & 100 & 100 \\
The severity of Dependence Scale (SDS) & $1.4(0.6)$ & 100 \\
Treatment Motivation (TMQ) & & $1.3(0.4)$ \\
$\quad$ External Motivation & $4.7(1.2)$ & $4.9(1.1)$ \\
Internal Motivation & $4.4(1.0)$ & $4.5(1.0)$ \\
Help & $5.8(1.1)$ & $5.9(1.0)$ \\
Confidence & $4.0(1.2)$ & $4.1(1.4)$ \\
\hline
\end{tabular}

\footnotetext{
${ }^{\mathrm{a}}$ Values are mean (SD), otherwise declared.
}

\subsection{Treatment engagement}

From the data collected in the period of 16 weeks from the three parameters of good engagement which are (1) completion and submission of homework, (2) participation in the session, and (3) understanding and able to recall the session's topic have showed that there are some differences between both group from all three parameters. Even though the performances are not consistent every week, we can see that the TAU+CM group has a higher level of score in all the three parameters. Multilevel analysis using GEE, however, did not show any significant differences of score between subjects from all the parameters, (1) homework completion (Wald- $\chi 2=1.005 ; \mathrm{p}=$ 0.316), (2) participation in session (Wald $-\chi 2=1.000 ; \mathrm{p}=0.317$ ) and (3) understanding of the topic (Wald- $\chi^{2}=$ $1.841 ; \mathrm{p}=0.175)$ thus rejecting the main hypothesis that there are no significant differences in performance in homework completion, participation and understanding between TAU+CM group with TAU group in the 16 weeks of study. 
However, during the period of 16 weeks both group showed a significant increase of performance weekly from week 1 to week 16 for all parameters observed (1) homework (Wald- $\chi 2=106.133 ; p=0.00$ ), (2) participation in session (Wald- $\chi 2=42.200 ; p=0.00$ ) and (3) understanding (Wald- $\chi 2=55.123 ; p=0.00$ ) (figure 3,4 and 5). In the three-parameter observed also showed significant differences at certain points of the week during the 16 weeks of study. Homework completion in week 5 have showed to have significant differences between TAU+CM group vs TAU group $(100 \%$ vs $77 \% ; \chi 2=7.813 ; \mathrm{p}=0.05)$. Week 5 also showed significant differences for participation $\left(56 \%\right.$ vs $\left.26 \%, \chi^{2}=3.852 ; \mathrm{p}=0.05\right)$ and understanding parameters $(56 \% \mathrm{vs} 26 \%, \chi 2=5.021 ; \mathrm{p}=$ $0.025)$. Understanding also showed another specific point of significant differences in week 10 of the study $(41 \%$ vs $\left.13 \%, \chi^{2}=5.750 ; p=0.016\right)$.

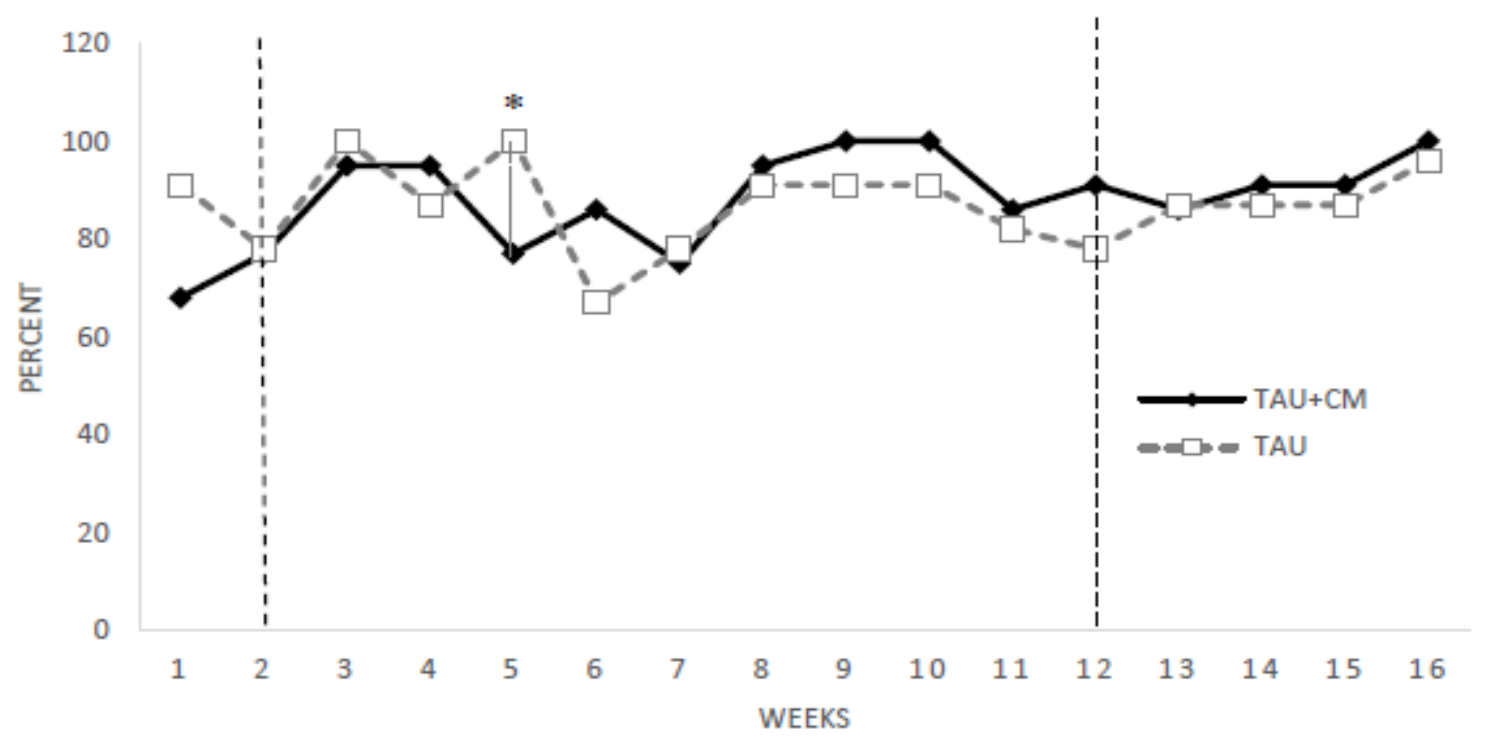

Figure 3. Subjects homework completion in the period of 16 weeks

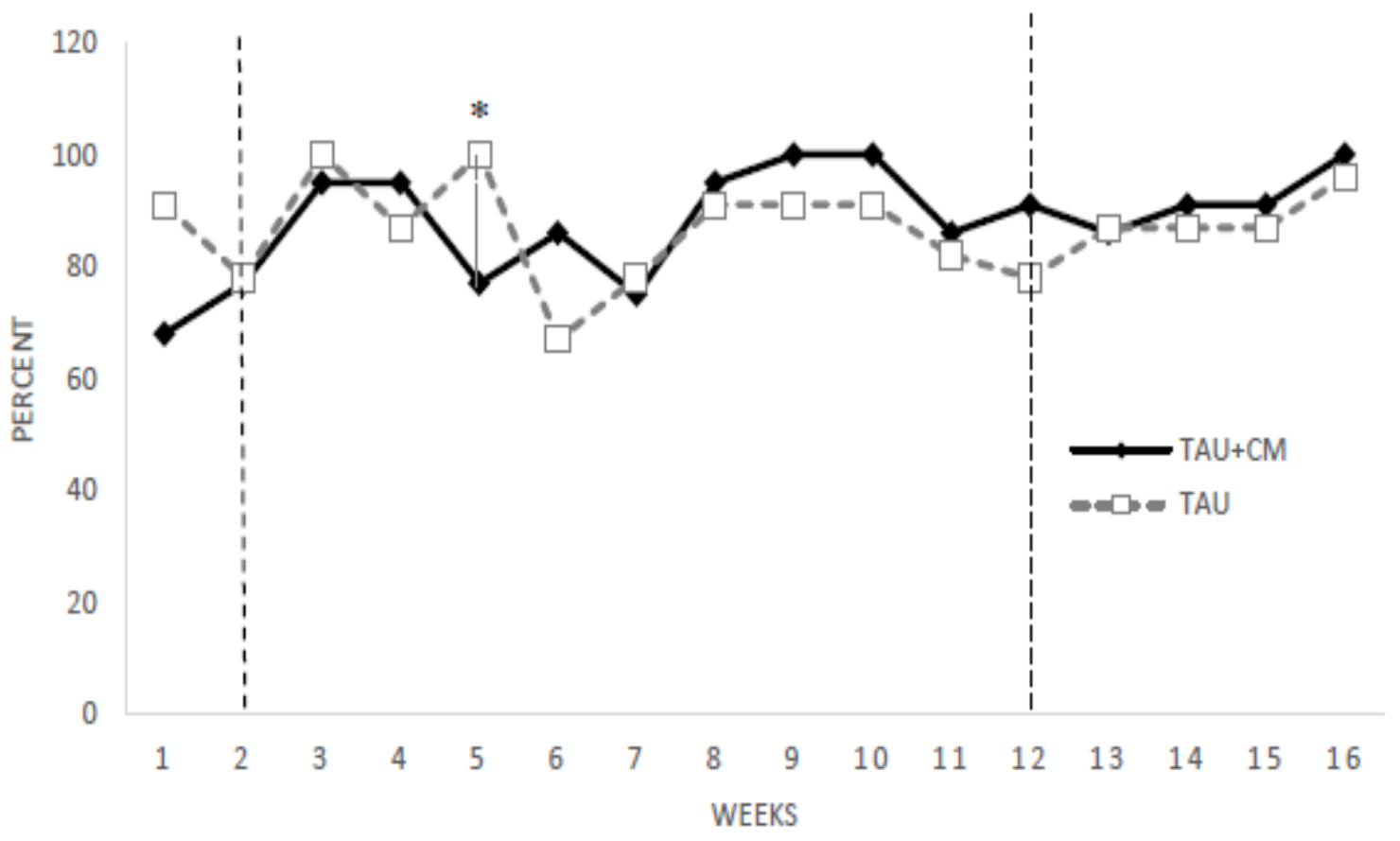

Figure 4. Subjects participation in the session for the period of 16 weeks 


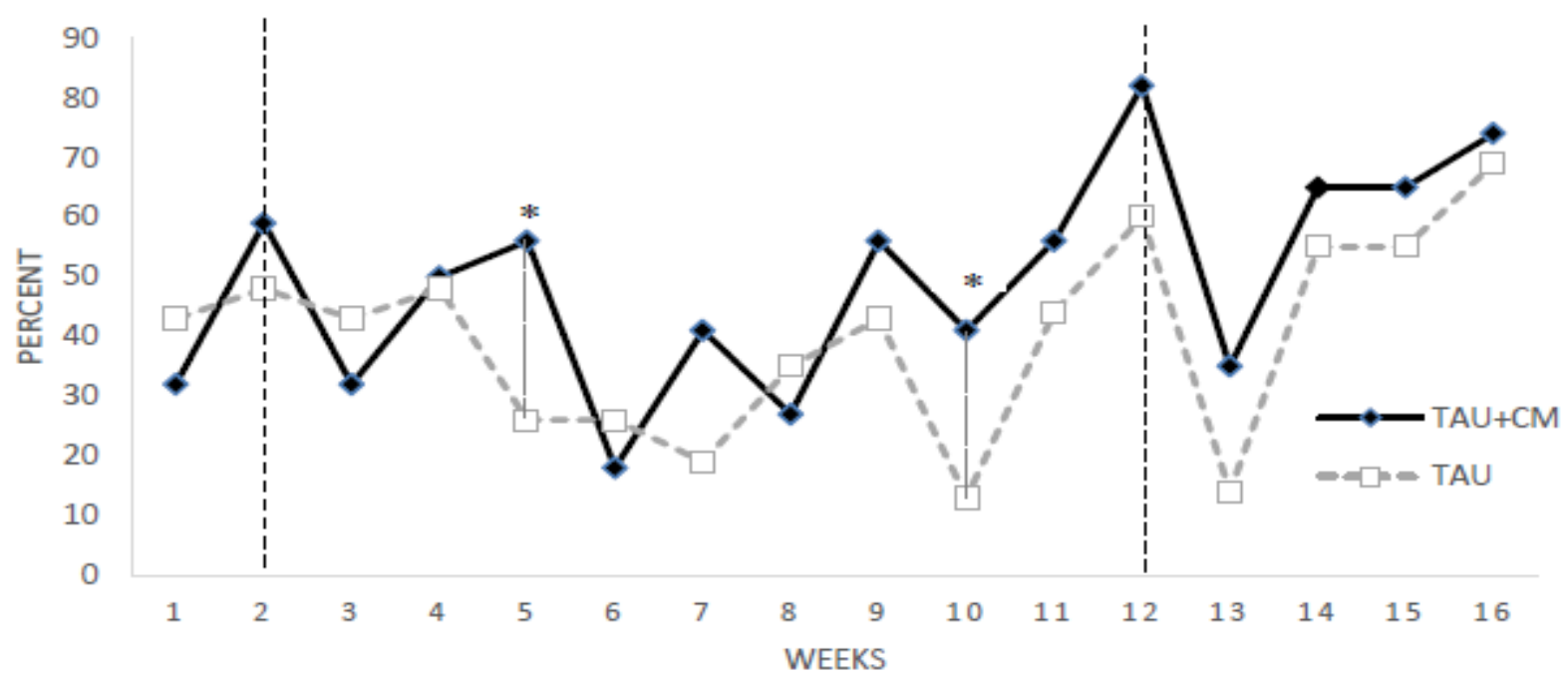

Figure 5. Subjects understanding in the session for the period of 16 weeks

An overall mean score of the three parameters was computed to form a new variable of weekly treatment engagement (Figure 6). From the study, the overall result showed that there are mean differences between both groups (TAU+CM vs TAU). However, statistically there are not significant. There are two points in the period of 16 weeks of study that show significant differences between groups which is in week-5 and week-10 (0.68 vs $0.48 ; t=2.511, \mathrm{p}=0.016$; and 0.62 vs $0.48 ; \mathrm{t}=2.208, \mathrm{p}=0.035)$. GEE analysis also showed no significant difference between the treatment group (Wald- $\chi^{2}=2.411 ; \mathrm{p}=0.120$ ), thus rejecting the main hypothesis. However, both group showed a significant increase over time in the period of 16 weeks (Wald- $\chi 2=6.019 ; \mathrm{p}=$ 0.014).

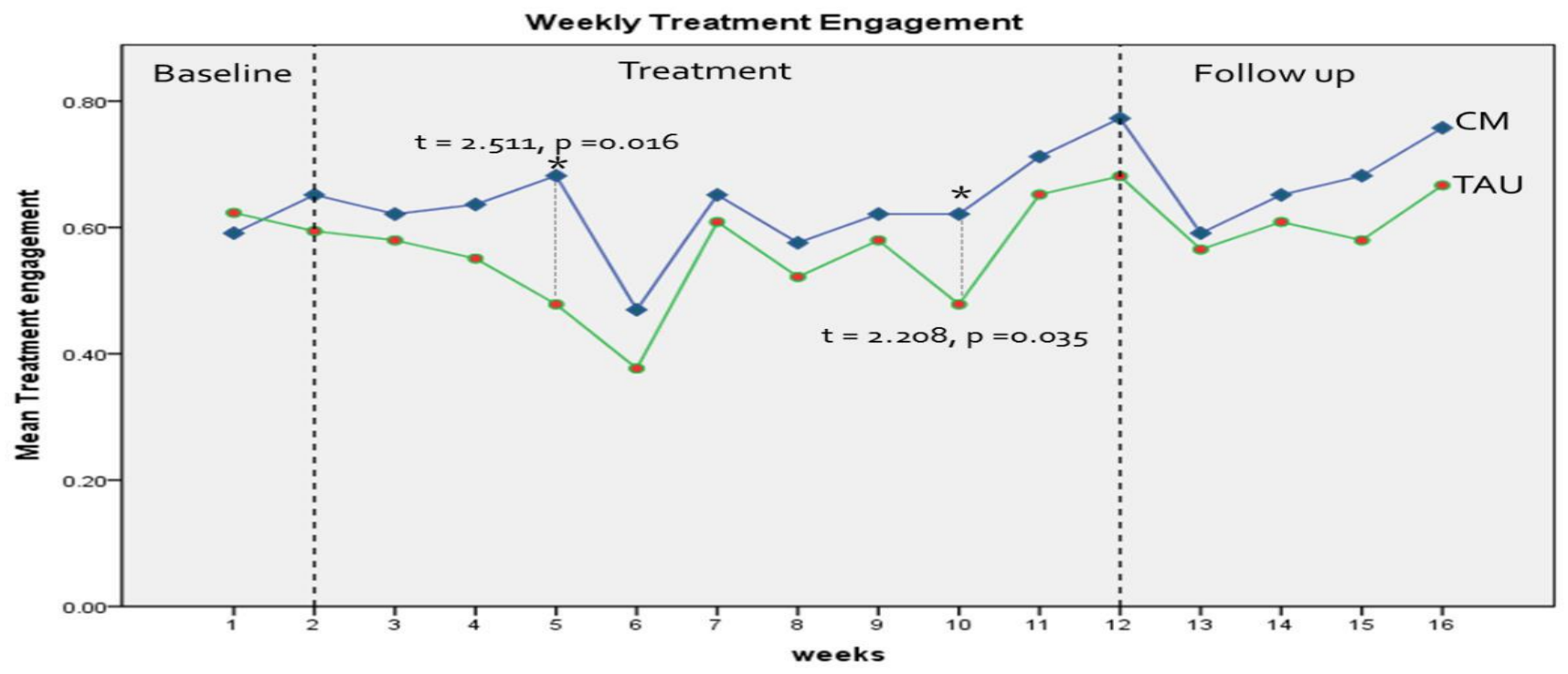

Figure 6. The overall mean of treatment engagement for the period of 16 weeks

\section{Discussion}

Based on the literature review extensively conducted, this study is probably the first CM study in the local context of Malaysia. This first attempt was done by conducting a randomized controlled trial study among drug addicts at a compulsory treatment rehabilitation center or CCRC. Previous research mostly conducted CM studies in an outpatient setting or in community-based with targeting on abstinence and adherence to treatment (Benishek, Dugosh \& Kirby, 2014; Davis et al., 2016; Prendergast, Podus, Finney, Greenwell, \& Roll, 2006). CM in a compulsory treatment center, focus on transforming positive behavior through targeted goals during the treatment session. 
The objective is to reinforce the aspect of good engagement toward treatment programs by using tangible CM reward to reinforce the positive behavior. Weekly observations from the first to the twelfth week of CM interventions in the study have showed an improvement in the achieve targeted goal compared to the control group without CM reinforcement. This finding is supported by previous studies that found CM to be effective in enhancing the effectiveness of existing programs compared to only existing programs (Gray, Carpenter \& Baker, 2011; Winstanley, Bigelow, Silverman, Johnson, \& Strain, 2011). However, this effect was seen only in a small mean difference and not statistically significant.

There are many factors that contributed to the outcome of the study, one of the major factors was the location of the study. The study was conducted in a compulsory rehabilitation center that uses coercion to achieve targeted behavior using disciplines, rules and regulations. Even though all precautions have been taken to reduce the effect of coercion during the study such as telling them that they will not be punished if they did not comply with the three parameters observed in every session. Based on Gendreau, Listwan, Kuhns, and Exum (2014), in their study of $\mathrm{CM}$, they found that one of the principles in conducting $\mathrm{CM}$ approach in a prison setting is that positive reinforcement must predominate over punishment by a ratio of 4:1 or even higher. In this case, even though the CCRC is not as tough as a prison, the positive effect of CM reinforcement still cannot overcome the effect of punishment in the center. Another factor that could contribute to the outcome of the study is the magnitude of the reinforcer or reward. As mentioned before, this study was the first research to study CM in Malaysia, one of the obstacles that the researcher had to face is the lack of reference in the local context especially in determining the suitable magnitude of CM reinforcer as well as getting the financial support to fund the study. Petry, Alessi, Barry and Carroll, (2015) have found that standard magnitude of reinforcer of the usual $\$ 300$ also efficacious compared to the higher magnitude of $\$ 900$. Some study also suggested that higher magnitudes of prize earning can improve CM effectiveness (Ghitza, Epstein, Schmittner, Vahabzadeh, Lin \& Preston, 2008). All previous studies were done in the West and developed countries seemed inappropriate as a guideline to determine the magnitude of reinforcer in the local context. It is hoped that this study will generate interest to conduct further studies in expanding the research of CM in the future.

\section{Conclusion}

There are huge opportunities to further investigate the efficacy of CM approach, especially in Malaysia. Customizing the implementation of CM to suit with Malaysian environment, setting and culture is a part of the study that can be investigated especially in a multiracial country such as Malaysia. Innovative ideas in the adaptation of $\mathrm{CM}$ such as making it reasonably low cost can benefit not only the treatment service provider, but also for the patient and to the government as the financial provider (Rash, Stitzer, \& Weinstock, 2016). The government has spent a lot of money for the treatment and rehabilitation of drug addicts and the cost increased each year. With the use of CM, it is hoping to help maintain the client in treatment and promote recovery and in the long run will save the country's expenses in handling other issues caused by addiction (Higgins et al., 2008). The future study is hoped to boost and extend the benefits of the existing treatment and rehabilitation programs with the focus on more evidence-based approach in Malaysian treatment setting.

\section{Acknowledgements}

This study was funded by Malaysia's National Anti-Drugs Agency (NADA) grant USIM/AADK/FKP/052003/43317.

\section{References}

Ali, J., Hassan, S., \& Karim, N. A. A. (2009). Kos Ekonomi Penyalahgunaan Dadah. Jurnal Antidadah Malaysia, 6(5), 107-121.

Bartholomew, N. G., Rowan-Szal, G. A., \& Simpson, D. D. (2005). Contingency Management Strategies and Ideas: A Planning guide for using rewards and start charts to reinforce goal setting, early engagement in treatment settings.

Benishek, L. A., Dugosh, K. L., Kirby, K. C., Matejkowski, J., Clements, N. T., Seymour, B. L., \& Festinger, D. S. (2014). Prize-based contingency management for the treatment of substance abusers: A meta-analysis. Addiction, 109(9), 1426-1436. https://doi.org/10.1111/add.12589 
Daly, J. C., \& Cohen, J. (1977). Statistical Power Analysis for the Behavioral Sciences, Revised Edition. Journal of the American Statistical Association (Revised Ed). New York: Academic Press. https://doi.org/10.2307/2286629

Davis, D. R., Kurti, A. N., Skelly, J. M., Redner, R., White, T. J., \& Higgins, S. T. (2016). A

review of the literature on contingency management in the treatment of substance use disorders, 2009-2014. Preventive Medicine, 92, 36-46. https://doi.org/10.1016/j.ypmed.2016.08.008

Gendreau, P., Listwan, S. J., Kuhns, J. B., \& Exum, M. L. (2014). Making Prisoners Accountable. Criminal Justice and Behavior, 41(9), 1079-1102. https://doi.org/10.1177/0093854814540288

Ghitza, U. E., Epstein, D. H., Schmittner, J., Vahabzadeh, M., Lin, J.-L., \& Preston, K. L. (2008). Effect of reinforcement probability and prize size on cocaine and heroin abstinence in prize-based contingency management. Journal of Applied Behavior Analysis, 41(4), 539-549. https://doi.org/10.1901/jaba.2008.41-539

Gray, K. M., Carpenter, M. J., Baker, N. L., Hartwell, K. J., Lewis, A. L., Hiott, D. W., ... Upadhyaya, H. P. (2011). Bupropion SR and contingency management for adolescent smoking cessation. Journal of Substance Abuse Treatment, 40(1), 77-86. https://doi.org/10.1016/j.jsat.2010.08.010

Higgins, S. T., \& Silverman, K. (2008). Contingency management. In The American Psychiatric Publishing textbook of substance abuse treatment (4th ed.) (pp. 387-399).

Lipsey, M. W. (1990). Design sensitivity: Statistical power for experimental research. California: Sage Publications.

Mahmood Nazar Mohamed, Zakaria, M., \& Hj Ghani, S. (2009). Keberkesanan Modul Model Matrix Untuk Pemulihan Penagih Dadah Dalam Setting Komuniti. Jurnal Antidadah Kebangsaan, 6(2). Retrieved from https://www.adk.gov.my/wp-content/uploads/jurnal_3.pdf

National Anti-Drugs Agency. Dasar Dadah Negara (2015). Retrieved from http://www.adk.gov.my/html/pdf/Buletin/dasardadahnegara.pdf

National Anti-Drugs Agency. (2016). Maklumat Dadah 2015. Retrieved from http://www.adk.gov.my/web/guest/dadah

Petry, N. M. (2000). A comprehensive guide to the application of contingency management procedures in clinical settings. Drug and Alcohol Dependence, 58, 9-25. https://doi.org/10.1016/S0376-8716(99)00071-X

Petry, N. M., Alessi, S. M., Barry, D., \& Carroll, K. M. (2015). Standard magnitude prize reinforcers can be as efficacious as larger magnitude reinforcers in cocaine-dependent methadone patients. Journal of Consulting and Clinical Psychology, 83(3), 464-472. https://doi.org/10.1037/a0037888

Petry, N. M., Tedford, J., Austin, M., Nich, C., Carroll, K. M., \& Rounsaville, B. J. (2004). Prize reinforcement contingency management for treating cocaine users: how low can we go, and with whom? Addiction, 99, 349-360. https://doi.org/10.1046/j.13600443.2004.00642.x

Prendergast, M., Podus, D., Finney, J., Greenwell, L., \& Roll, J. (2006). Contingency management for treatment of substance use disorders: a meta-analysis. Addiction, 101(11), 1546-1560. https://doi.org/10.1111/j.1360-0443.2006.01581.x

Rash, C. J., Stitzer, M., \& Weinstock, J. (2016). Contingency management: New directions and remaining challenges for an evidence-based intervention. Journal of Substance Abuse Treatment. https://doi.org/10.1016/j.jsat.2016.09.008

Ting Chie, Q., Lian Tam, C., Bonn, G., Minh Dang, H., \& Khairuddin, R. (2016). substance abuse, relapse, and Treatment Program evaluation in Malaysia: Perspective of rehab Patients and staff Using the Mixed Method approach. Frontiers in Psychiatry, 7(90), 1-13. https://doi.org/10.3389/fpsyt.2016.00090

U.S. Department of Health and Human Services. (1999). Treatment Improvement Protocol Series 35. In Enhancing Motivation for Change in Substance Abuse Treatment (pp. 1-273). https://doi.org/10.1007/SpringerReference_84753

United Nations Office on Drugs and Crime. (2016). World Drug Report 2016. New York. Retrieved from http://www.unodc.org/doc/wdr2016/WORLD_DRUG_REPORT_2016_web.pdf

Winstanley, E. L., Bigelow, G. E., Silverman, K., Johnson, R. E., \& Strain, E. C. (2011). A randomized controlled trial of fluoxetine in the treatment of cocaine dependence among methadone-maintained patients. Journal of Substance Abuse Treatment, 40(3), 255-264. https://doi.org/10.1016/j.jsat.2010.11.010 